Revista de Economia Política, vol. 38, $n^{\circ} 3$ (152), pp. 526-547, julho-setembro/2018

\title{
Governos Lula e Dilma em matéria de seguridade social e acesso à educação superior
}

\author{
Lula and Dilma governments in terms of social \\ security and access to higher education
}

ROSA MARIA MARQUES*

SALOMÃO BARROS XIMENES**

CAMILA KIMIE UGINO***

\begin{abstract}
RESUMO: O artigo faz um balanço das políticas sociais desenvolvidas no Brasil pelos governos Lula e Dilma (2003 - 2016). Nosso enfoque são as políticas de Seguridade Social e de acesso à educação superior, cuja apresentação e análise fazemos em quatro partes. A primeira é dedicada ao Programa Bolsa Família, considerado o carro-chefe dos programas sociais do PT. A segunda parte trata da Previdência Social e da política de valorização do salário mínimo; a terceira analisa aspectos da Saúde e do Sistema Único de Saúde (SUS) e a quarta aborda a política de acesso à educação superior. Conclui-se que as políticas sociais realizadas pelos governos Lula e Dilma apresentam um duplo caráter. De um lado, não há dúvida de que constituíram um avanço, melhorando as condições de vida e de reprodução das parcelas mais pobres do país, sobretudo por conta do Programa Bolsa Família, da valorização do salário mínimo e, para uma menor parcela, do acesso à educação superior gratuita. De outro lado, percebe-se que a via ou o instrumento eleito para que essa melhora ocorresse foi a renda ou o salário, mantendo-se, em geral, sem alteração as estruturas seculares que geram a pobreza e a desigualdade no país. Ao mesmo tempo, tais governos foram determinantes na consolidação do setor privado em aéreas de política social, inflando a pressão por privatização que tenderá a se acentuar nos próximos anos.
\end{abstract}

\footnotetext{
* Professora titular do Departamento de Economia e do Programa de Estudos Pós-graduados em Economia Política da Pontifícia Universidade Católica de São Paulo - PUC. E-mail: rosamkmarques@ gmail.com.

** Professor adjunto do Centro de Engenharia, Modelagem e Ciências Sociais Aplicadas e do Programa de Pós-graduação em Políticas Públicas da Universidade Federal do ABC - UFABC. E-mail: salomaoximenes@gmail.com.

*** Professora de graduação do Departamento de Economia da Pontifícia Universidade Católica de São Paulo - PUC. E-mail: camila.ugino@gmail.com. Submetido: 17/Outubro/2016; Aprovado: 1/ Dezembro/2017.
} 
PALAVRAS-CHAVE: Políticas Sociais; Previdência e Saúde; Salário Mínimo; Programa Bolsa Família; Educação Superior.

ABSTRACT: The article analyzes the social policies developed in Brazil by the Lula and Dilma governments (2003-2016). The focus is the Social Security and the access to higher education policies, presented and analyzed in four parts. The first is dedicated to the Bolsa Família Program, considered the flagship of PT's social programs. The second part deals with Social Security and the policy of valorization of the minimum wage; the third examines aspects of Health and the Unified Health System (SUS) and the fourth addresses the policy of access to higher education. It is concluded that the social policies carried out by the Lula and Dilma governments have a twofold character. On the one hand, they have undoubtedly been a step forward, improving living and reproductive conditions in the poorest parts of the country, especially because of the Bolsa Família Program, the valuation of the minimum wage and, to a smaller part, access to education. On the other hand, it can be seen that the path or instruments chosen for this improvement was income or wages, and the secular structures that generate poverty and inequality in the country are generally unchanged. At the same time, such governments were decisive in consolidating the private sector in social policy areas, inflating the pressure for privatization that will tend to intensify in the coming years.

KEYWORDS: Social Policy; Social Security And Health; Minimum Wage; Bolsa Família Program; Higher Education.

JEL Classification: H5; I18; I2; J3.

\section{INTRODUÇÃO}

Afastada Dilma Rousseff da Presidência da República, qual o balanço que se pode fazer das políticas sociais desenvolvidas pelos governos capitaneados pelo Partido dos Trabalhadores (PT)? Durante o período 2003-2015, as políticas realizadas nesse campo sempre foram objeto de intensa discussão, tanto entre os especialistas como entre seus críticos, fossem eles posicionados à esquerda do Partido dos Trabalhadores (PT) ou à direita. Pelo lado dessa esquerda, elas foram vistas, na melhor das avaliações, como limitadas, posto que não foram associadas a medidas que promovessem alteração da estrutura oligárquica e desigual da sociedade brasileira. Mas também algumas das medidas adotadas por esses governos foram entendidas, por essa mesma esquerda, como retirada de direitos dos trabalhadores. De maneira geral, a ideia era que as políticas sociais desses governos não tinham a centralidade que o discurso oficial propagava, sendo residual e dependente da política macroeconômica fundada no tripé meta de inflação, superávit primário e câmbio flexível, que sempre esteve a serviço do cumprimento dos interesses dos credores da dívida pública.

Pelo lado da direita, principalmente aquela que se expressa na grande mídia televisiva e escrita, as críticas foram muitas: começando pelos efeitos da política de transferência de renda (Programa Bolsa Família) nos salários da base da pirâmide do mercado de trabalho, que impedem a contratação de trabalhadores a qualquer 
preço pelo Brasil afora, tal como antes; passando pela responsabilização em parte do aumento real do salário mínimo pela elevação do custo da mão de obra e pela não competitividade dos produtos brasileiros no exterior; e terminando por apontar que a trajetória do gasto social estava descontrolada e que isso impedia a manutenção de um crescimento sustentável. Isso tudo sem considerar as avaliações de outro cunho, que advoga que a pessoa apta ao trabalho, embora extremamente pobre, não deve receber auxílio pecuniário, pois tal ação só reforça o lado preguiçoso das pessoas (sic).

No corpo deste artigo, não vamos analisar todo o conjunto de políticas desenvolvidas pelos governos Lula e Dilma que poderiam ser entendidas como sociais. Elas estão presentes em diversas áreas e são muitas - tais como habitação (Minha Casa Minha Vida e a abertura de empréstimos para a compra de casa própria), educação (Prouni, Fies, política de cotas, criação de quase uma vintena de novas universidades e ampliação de vagas públicas na educação superior), saúde, previdência, assistência social, mercado de trabalho (aumento expressivo do rendimento real médio e o mais baixo nível de desemprego), integração social, entre outras. Atemo-nos ao que tradicionalmente é considerado integrante da proteção social garantida e/ou organizada pelo Estado, isto é, aquela contemplada pela Seguridade Social, mais o Programa Bolsa Família, o salário mínimo, mas também abordamos a política voltada à educação no nível superior pela importância que ela assume no debate nacional. Já são suficientes temas para serem abordados em um balanço do que foram as políticas sociais nos governos encabeçados pelo PT. Além desta introdução, o texto está dividido em quatro partes. A primeira é dedicada ao Programa Bolsa Família (BF), considerado o carro-chefe dos programas sociais do PT. A segunda parte trata da Previdência Social e da política de valorização do salário mínimo; a terceira analisa aspectos da Saúde e do Sistema Único de Saúde (SUS) e a quarta aborda a política de acesso à educação superior. O texto é finalizado com breves considerações finais.

\section{VOLTANDO-SE PARA OS MUITO POBRES}

O Programa Bolsa Família (BF), introduzido por Lula em $2003^{1}$, é o principal instrumento de transferência de renda existente no Brasil, caso não seja considerado o impacto do benefício assistencial (Benefício de Prestação Continuada - BPC) e do piso de um salário mínimo do Regime Geral de Previdência Social (RGPS) pago aos trabalhadores rurais e urbanos. À diferença desses últimos, que foram instituídos pela Constituição de 1988 e pelas leis que a regulamentam em matéria

\footnotetext{
${ }^{1}$ O BF foi instituído em 10/2003 mediante a Medida Provisória 132, convertida na Lei 10.836, de 9/01/2004. A partir de sua vigência, os programas então existentes - Programa Nacional de Renda Mínima vinculado à Educação - Bolsa Escola (2001), o Programa Nacional de Acesso à Alimentação - PNAA (2003), o Programa Nacional de Renda Mínima vinculada à Saúde - Bolsa Alimentação (2001) e o Programa Auxílio-Gás (2002) foram extintos.
} 
de Previdência e Assistência Social, não constitui um direito e é parte integrante de um programa. Isso significa que, em tese, pode sofrer descontinuidade ou alterações sem exigir mudança constitucional. Não é por acaso que o documento "A Travessia Social” (Estadão, 2016), elaborado pela Fundação Ulysses Guimarães, ligada ao Partido do Movimento Democrático Brasileiro (PMDB), a que é filiado Michel Temer, propõe que o BF seja dirigido somente aos $5 \%$ mais pobres da população brasileira, o que corresponde a cerca de 10 milhões de pessoas, bem distante do total de beneficiários do programa no início de 2016 (cerca de 14 milhões de famílias, o que corresponde a $28 \%$ da população). O gasto com o BF é pouco superior a $0,5 \%$ do PIB.

O BF consiste de dois benefícios: o Básico, dirigido às famílias situadas na extrema pobreza (renda per capita até $\mathrm{R} \$ 85,00$ mensais) e o Variável, dirigido a famílias pobres com renda per capita entre R \$ 85,01 e R \$170,00 mensais, desde que tenham crianças ou adolescentes de 0 a 17 anos. $O$ primeiro não está sujeito a condicionalidades, aproximando-se, por isso, de um tipo de renda mínima, dirigido à parcela mais pobre da população. O quanto cada família recebe é resultado do somatório dos benefícios recebidos, que dependem da composição familiar e de sua renda. O máximo de benefício variável que uma família pode acumular é cinco. Em seu início, o BF restringia-se ao Benefício Único e Variável, dirigido a famílias com crianças de até 15 anos de idade. No governo Dilma, ele foi ampliado para contemplar outras situações, de modo a focalizar na gestante, na nutriz, nos adolescentes de 16 e 17 anos de baixa renda, e com o intuito de auxiliara na superação da extrema pobreza.

A estimativa da quantidade de famílias passíveis de ser objeto do BF é realizada pelo Instituto Brasileiro de Geografia e Estatística (IBGE), mas as informações relativas às famílias, em cada município, integram o Cadastro Único para Programas Sociais, monitorado pelo ministério responsável pelo programa (antes Ministério do Desenvolvimento Social e Combate à Fome e, após o afastamento de Dilma Rousseff, Ministério do Desenvolvimento Social e Agrário). As informações dos beneficiários do BF são de domínio público, de modo que qualquer pessoa pode acessar o banco de dados administrado pela Caixa Econômica Federal e ver o nome e a data de nascimento da pessoa responsável pelo recebimento do benefício, bem como de seus filhos. Ressalte-se que o artigo 23 da Lei 10.836/2004 garante que a mulher seja preferencialmente a titular do cartão de benefícios, dando ênfase ao papel da mãe na estrutura familiar, muito embora o BF utilize o conceito de unidade nuclear e não de unidade familiar. Vários estudos apontam que essa "preferência" (que é adotada internacionalmente em matéria de assistência social) teve grande impacto no empoderamento das mulheres, muitas vezes chefe de famílias monoparentais. Como não poderia deixar de ser, a distribuição regional do BF é fortemente concentrada na região Nordeste, a mais pobre do país, seguida da região Sudeste, a mais populosa.

Vários foram os impactos da introdução do Programa Bolsa Família. O primeiro deles, para além de seu objetivo explícito, foi auxiliar na formação de uma nova base social de apoio ao governo, diferente da sua tradicional, isto é, vincula- 
da aos sindicatos, aos movimentos sociais e ao PT (Marques et al, 2009). Essa é a mesma conclusão a que chega André Singer (2009). Outro importante efeito diz respeito à injeção de recursos que os benefícios pagos representam nos municípios mais pobres, superando, em alguns casos, em $40 \%$ a receita disponível dos mesmos (receita provinda de arrecadação própria mais as transferências constitucionais) (Marques, 2005). A isso se somam os estudos relativos a seu efeito multiplicador, movimentando as economias locais (Neri, 2013).

Por outro lado, estudos apontam que os beneficiários do BF não apresentaram maior nível de cobertura vacinal do que a população de baixa renda não coberta pelo programa (Sawyer, 2007) e que a frequência escolar aumentou relativamente pouco ( 2,2 pontos percentuais), tendo sido maior na região Nordeste do que na região Sudeste $\left(2,2\right.$ e 1,5 pontos percentuais, respectivamente) ${ }^{2}$ (Silveira Neto, 2010). $\mathrm{Na}$ área da saúde, considerando um de seus principais indicadores (taxa de mortalidade infantil em crianças menores do que 5 anos de idade), $17 \%$ da redução observada no período 2004-2009 são atribuídos ao BF (Rasella, 2013).

Outros estudos estimaram o impacto do BF na redução da pobreza e na desigualdade de renda. Segundo o Instituto de Pesquisa Aplicada (IPEA, 2010), a população situada abaixo da linha de pobreza (definida internacionalmente como US\$ PPC $^{3} 1,25 \mathrm{dia}$ ), que correspondia a $12 \%$ da população brasileira um ano antes do início da implantação do BF, havia caído para 4,8\% em 2008. A pobreza, por sua vez, caiu de $26,1 \%$ para $14,1 \%$ da população no mesmo período. Já quanto à desigualdade da renda, 16\% da redução ocorrida entre 1999 e 2009 são atribuídos ao BF, embora esse benefício não chegue a representar $0,8 \%$ da renda das famílias (Soares et al., 2010). Segundo esses autores, essa aparente contradição explica-se pela alta focalização do programa, isto é, pelo fato de o benefício ser destinado aos mais pobres. Ainda de acordo com esses autores, a presença do BF é fator explicativo do aceleramento da redução da pobreza e da extrema pobreza nos anos 2000.

Apesar dos impactos positivos do BF, do simples fato de sua existência ter melhorado a condição de vida de milhões de brasileiros e de o mesmo ser reconhecido mundialmente, o programa recebeu e recebe vários tipos de crítica, como anteriormente mencionado. No campo da esquerda, destacam-se pelo menos duas: o fato de não ter sido acompanhado por medidas que eliminassem os determinantes da pobreza no país e de ser identificado como um programa inspirado pelo Banco Mundial. Com respeito à primeira crítica, não há o que dizer, pois, independentemente das causas que se atribui à pobreza, os governos do PT não alteraram (ou mesmo se propuseram a isso) as bases sobre as quais se reproduz a sociedade brasileira.

Já em relação à inspiração atribuída ao Banco Mundial, é preciso se recuperar alguns pontos. É fato que, além do Brasil, vários países da América Latina desenvolveram políticas de transferência de renda condicionada. Elas integram a segun-

\footnotetext{
${ }^{2}$ Esses resultados foram altamente influenciados pelo fato de a frequência escolar já ser de $95,7 \%$ na região Nordeste e de $97,3 \%$ na Sudeste.

${ }^{3}$ Paridade de Poder de Compra.
} 
da geração de políticas assistências introduzidas na região quando ficou evidente que as políticas macroeconômicas neoliberais tiveram como resultado a persistência da pobreza e o aumento significativo do número de pessoas em situação de "vulnerabilidade social"4. Segundo a Cepal (2009, p. 94), a criação de uma nova geração de políticas sociais associadas ao combate à pobreza expressou "o reconhecimento dos escassos avanços em matéria de redução da pobreza" durante os anos 1990. As políticas focalizadas de segunda geração são políticas "massivas" (dado o número de pessoas por elas contempladas), contrastando com aquelas voltadas a determinadas comunidades, típicas das políticas focalizadas de primeira geração. Segundo Solano (2009), ao se referir a um trabalho do Programa de las Naciones Unidas para el Desarrollo (PNUD) e a outro do Banco Mundial, todos os programas que integram essa nova geração de políticas sociais focalizadas têm pelo menos três elementos em comum: o foco em famílias pobres ou extremamente pobres, com crianças e adolescentes; o princípio da contrapartida (ou condicionalidade) e a ideia de "acumulação de capital humano" ${ }^{5}$ no longo prazo.

Não há dúvida quanto ao apoio dado pelo Banco Mundial a essas iniciativas. Mas esse apoio pode ser entendido como uma mudança parcial de sua posição anterior, pois previamente defendia que a não redução da pobreza nos anos 1990, quando na maioria dos países da América Latina foram implantadas políticas neoliberais, devia-se a problemas de "governança" (Banco MundIAL, 2000). E não há "desgovernança" que explique a necessidade de políticas de transferência de renda massivas, tais como a realizada no Brasil. No país, não só os recursos destinados ao BF integram a Seguridade Social, tendo origem em contribuição, como a concepção do programa tem suas raízes na proposta de renda mínima garantida defendida por Eduardo Suplicy, que foi muito discutida no país, nos anos 1990. Reforça esse tipo de interpretação, o fato de o BF ter um componente - o Benefício Básico - que não exige contrapartida. A existência de um benefício dirigido às famílias extremamente pobres, sem que lhe seja exigido o cumprimento de qualquer condicionalidade, pode ser entendida como um embrião de renda mínima garantida, apesar de apenas direcionada à população miserável.

Dessa forma, desqualificar o BF porque o Banco Mundial (BM) apoia políticas de transferência de renda é no mínimo estranho, para não dizer que é puramente animado por interpretações maniqueístas, isto é, se o BM apoia, "somos contra". O relevante a discutir é se a política de transferência de renda no Brasil - O Pro-

\footnotetext{
${ }^{4}$ A expressão "vulnerabilidade social” remete à consideração das características dos indivíduos como responsáveis por sua situação. Com isso, deixa-se de levar em conta que, na sociedade capitalista, os diferentes segmentos sociais e econômicos estão submetidos à lógica da acumulação do capital. Se no plano da aparência, os setores pobres ou muito pobres parecem estar excluídos, integram o chamado exército industrial de reserva, viabilizando taxas de exploração elevadas (Marx, 1982). A expressão é utilizada pela Comissão Econômica para a América Latina e o Caribe (Cepal, 2000)

${ }^{5}$ Isto é, que os beneficiários das políticas, principalmente as crianças e os adolescentes, iriam portar capacidades qualitativamente diferentes que seus genitores, decorrentes do exercício das contrapartidas exigidas.
} 
grama Bolsa Família - foi (é) acompanhada pela defesa da privatização da proteção social e pela destinação de ações e serviços públicos, especialmente na área da saúde, somente aos mais pobres, tal como o Banco defendeu abertamente em alguns momentos. Apesar dos problemas enfrentados no campo da proteção social mais identificada com a Seguridade Social, tal como é exposto adiante, esse não foi o caso no Brasil. A implantação do BF não provocou um deslocamento da presença do Estado na proteção social estruturada na Constituição de 1988.

\section{A PREVIDÊNCIA SOCIAL E O SALÁRIO MÍNIMO}

No campo da Previdência Social, os governos do PT serão lembrados de maneira contraditória. De início, no primeiro ano de Lula, foi encaminhada proposta de reforma que alterou as condições de acesso dos servidores públicos à aposentadoria (incorporação do critério de idade) e que introduziu a contribuição dos aposentados, fossem eles servidores ou não. Essas propostas coincidiam com aquelas que haviam sido rechaçadas quando da reforma previdenciária realizada por Fernando Henrique Cardoso ${ }^{6}$, sobre a qual o PT havia se manifestado contra. Não foi por outro motivo que tal encaminhamento teve como resultado a expulsão das fileiras do partido da senadora Heloisa Helena e dos deputados federais Luciana Genro, João "Babá” Batista Araújo e João Fontes, por não aceitarem fazer a defesa da proposta do governo, que nunca havia sido discutida no interior do PT.

Um dos aspectos que chamou a atenção, na época, foi o fato de o texto da exposição dos motivos retomar argumentos até então usados por aqueles situados nas fileiras neoliberais e de dar exemplos sem nenhum cuidado estatístico, deturpando fatos sem cerimônia (Marques e Mendes, 2005). Quanto às propostas, além da introdução do critério de idade, sempre combatida pelas centrais sindicais e pelos movimentos sociais, mas passível de ser discutida no campo previdenciário, dado que o processo de envelhecimento constitui uma realidade mundial que altera os parâmetros sobre os quais foram construídos os sistemas previdenciários atuais, destaca-se a cobrança de uma contribuição dos aposentados. Em 7 de agosto de 2003, pela Câmara, e em 19 de dezembro de 2003, pelo Senado, foi aprovada a proposta de reforma previdenciária $\mathrm{n}^{\circ} 29$, encaminhada pelo governo Lula em 29 de abril de 2003. Em curto espaço de tempo e com base na autoridade de sua expressiva votação (61,27\% dos votos no segundo turno), estava aprovado aquilo que antes pareceria impossível. Tentada e derrotada por três vezes durante o governo FHC, e sempre contando com o voto contrário do PT, a contribuição dos aposentados passou a ser uma realidade. Antes de Lula, somente o último governo militar, de João Baptista Figueiredo, ousou cobrar de aposentados, no caso, dos segurados do então Instituto Nacional de Previdência Social (INPS). Instituída em

\footnotetext{
${ }^{6}$ A cobrança de uma contribuição dos aposentados servidores foi tentada em várias oportunidades, inclusive em alguns estados, tendo sido sempre derrotada.
} 
1981 e consistindo uma alíquota de 3\% a 5\%, a cobrança foi extinta em 1984. Tal como nos anos 1980, os argumentos contrários a essa iniciativa continuam os mesmos: a contribuição dá origem a um direito futuro e, por isso, não há como exigir que o aposentado contribua, posto que ele não usufruirá de outro benefício. Sua cobrança significa a quebra de um dos princípios mais fundamentais da doutrina previdenciária, o da equidade na participação do custeio. Ao final, o governo Lula aprovou a contribuição de $11 \%$ para os aposentados, muito embora, em função da resistência, tenha sido obrigado a isentar as aposentadorias de valores mais baixos.

O segundo aspecto previdenciário que será lembrado do governo do PT é a introdução da fórmula 85/95, já no último ano do primeiro governo Dilma. Primeiramente encaminhada por uma Medida Provisória (MP 676/15) e depois tornada Lei (13.183, de 04/11/15), essa medida veio melhorar sensivelmente o valor do benefício dos futuros aposentados, que puderam, a partir daí, escolher entre as regras até então vigentes e a fórmula 85/95. Na Lei que regulamenta a reforma previdenciária promovida por FHC (9.876/99), o critério de idade mínima que não havia sido aprovado no Congresso Nacional, reapareceu mediante o que passou a ser conhecido como fator previdenciário.

Sobre o valor do benefício calculado (cuja base também foi alterada na época), passou a incidir um redutor (o fator) que varia de acordo com a idade do segurado, levando em conta os anos de sobrevida, em média, que terá o aposentado, e segundo as estimativas do IBGE. Sobre isso, assim disse o Departamento Intersindical de Estatística e Estudos Socioeconômicos (Dieese):

Sem ter incorporado a proposta de limite mínimo de idade para a aposentadoria dos já inscritos no sistema (60 anos para mulheres e 65 anos para os homens), previsto originalmente pelo executivo quando do envio da PEC $\mathrm{n}^{\circ} 20[\ldots]$ a nova legislação previdenciária optou pelo incentivo à permanência em atividade do trabalhador, mediante uma modalidade de cálculo em que o benefício é diminuído caso ele seja jovem ou tenha pouco tempo de contribuição, mas que aumenta à medida que a concessão da aposentadoria é adiada (Dieese, 2001, p. 252).

Já Solange Paiva Vieira, mentora da fórmula de cálculo do fator previdenciário, então assessora especial do Ministério da Previdência e Assistência Social (MPAS), em entrevista à revista Conjuntura Econômica assim afirmou:

Fiz então a conta de trás para frente, com variáveis como a expectativa de vida, fluxo de caixa, tempo de contribuição e a taxa de juros implícita. Eu peguei tempo de contribuição por expectativa de sobrevida e multipliquei o tempo de contribuição pela alíquota contributiva. [...] A gente fez uma captação virtual. [...] É uma capitalização [...] tem uma capitalização com uma taxa de juros que varia entre $2,5 \%$ e $4,5 \%$. Taxa real, dependendo da idade em que a pessoa se aposenta. Está lá, é 
o que a pessoa contribui, corrigido por essa taxa de juros ao ano (FGV, 2001, p. 58).

O resultado da aplicação do fator provocou, como esperado, o adiamento da entrada de solicitação de aposentadoria. Se, em 1998, 77,3\% das novas aposentadorias urbanas por tempo de contribuição foram concedidas para segurados com idade entre 45 a 64 anos, em 2008 esse percentual já havia aumentado para 96,1\% e, em 2014, já somava 97,0\%. E o impacto do fator no adiamento se fez sentir mais sobre as mulheres do que os homens: enquanto, em 1998, 72,8\% das mulheres e $78,7 \%$ dos homens haviam solicitado aposentadoria com idade entre 45 e 64 anos, em 2008 esse percentual foi de $96,4 \%$ para mulheres e 95,9\% para homens, e, em 2014, último dado disponível, esse percentual foi de $97,0 \%$ para mulheres e $97,1 \%$ para homens. Essa evolução mostra que o fator reduziu a diferença que havia entre homens e mulheres em relação à idade de solicitação de aposentadoria por tempo de contribuição. Entre os anos 1998 e 2008, a idade média das mulheres passou de 48,5 anos para 51,3 anos, e a dos homens, de 50,1 anos para 53,9 anos. Em 2014, a idade média já foi de 52,3 anos e 55,1 anos, respectivamente (MINISTÉRIO DA PREVIDÊNCIA SOCIAL, 2016).

Desde a entrada em vigor do fator previdenciário, foi forte a campanha para sua revogação. Entre os que lutaram para derrubá-lo, além das centrais sindicais e dos movimentos sociais, destacou-se o senador Paulo Paim (PT). É a partir dessa luta que, em 2015, Dilma editou a Medida Provisória 676/15, introduzindo a fórmula $85 / 95$ que, comparada ao fator, é mais vantajosa para os trabalhadores. Essa fórmula mantém o tempo de contribuição anteriormente exigido e estipula uma idade mínima (30 e 55, para mulheres; 35 e 60 para homens, respectivamente). Assim, o critério da idade, que estava implícito na fórmula do fator, foi explicitado, mas com uma idade fixa. O resultado prático foi que o benefício é de valor maior do que seria quando aplicado o fator. Isso não significa, entretanto, que a fórmula 85/95 não considere o contínuo envelhecimento da população brasileira. Nela está previsto que, a partir de 2019, com vigência por dois anos, seja aumentada em um ano a idade tanto para homem como para mulher, e assim sucessivamente.

Além de garantir um valor de aposentadoria maior com relação ao fator previdenciário, a fórmula 85/95 é mais favorável aos trabalhadores, pois contempla as diversas realidades do mercado de trabalho formal do país. Em outras palavras, os que começam a trabalhar mais cedo e para a Previdência contribuem, poderão se aposentar também mais cedo.

Um terceiro elemento que irá marcar a trajetória dos governos do PT com relação à Previdência Social é a elevação do valor real do piso dos benefícios, fruto da política de valorização do salário mínimo iniciada no governo Lula. Essa política foi respaldada pela ação conjunta das Centrais Sindicais que, em 2004, realizaram três marchas a Brasília com o intuito de pressionarem os poderes Executivo e Legislativo a apoiarem a iniciativa. O resultado foi o aumento do salário mínimo, em termos reais, de 54\% entre dezembro de 2002 e dezembro de 2010 . De acordo com estimativa do Dieese, isso afetou positivamente 47 milhões de pessoas, entre 
trabalhadores e aposentados, pois o benefício mínimo pago pela Previdência e pela Assistência Social está, desde a Constituição de 1988, indexado ao salário mínimo. Essa indexação tornou o piso dos benefícios um poderoso elemento redistribuidor de renda. O estudo de Soares et al. (2010), aqui já citado, mostra que $15 \%$ da queda observada no índice Gini no período 1999-2009 deve-se aos benefícios indexados ao salário mínimo. No governo Dilma, foi dado prosseguimento à política de valorização do salário mínimo, mas seu aumento perdeu impulso (valorização real de 18,74\%). Vale lembrar que, em 2011, mediante a Lei 12.382, de 25 de fevereiro, foi definido um critério objetivo para definir o reajuste: o índice da inflação do ano anterior, acrescido da taxa de crescimento da economia dos dois últimos anos.

Por último, o quarto elemento, que configura a política do governo PT com relação à Previdência, foi o anúncio, no início de 2016, de que Dilma estaria estudando a possibilidade da introdução de idade mínima para o acesso à aposentadoria. Evidentemente que isso não foi adiante, dado o impeachment ocorrido. Contudo, tal proposta faz parte da "Ponte para o futuro", documento do PMDB que sintetiza as propostas que a oposição aos governos do PT pretende implantar no Brasil. Em relação à aposentaria, o documento se refere à introdução do critério de idade, de 60 e 65 anos, para mulheres e homens, respectivamente. Mas essa formulação já evoluiu para a defesa de uma idade única (65 anos), para ambos os sexos.

Ainda durante boa parte do governo Dilma, destacou-se sua política de desonerar as empresas das contribuições sociais calculadas sobre os salários, no intuito declarado de tornar os produtos brasileiros mais competitivos no mercado internacional. Iniciada em dezembro de 2011, a desoneração sobre a folha (em parte substituída por uma contribuição sobre a receita bruta) atingia 56 setores de atividade industrial (a maior parte), comercial, transporte e serviços em setembro de 2015. Essa política aprofundou os problemas de financiamento da Previdência Social, e serviu para aprofundar o argumento da necessidade de sua reforma. Como o próprio Ministério da Fazenda previa, os recursos arrecadados sobre a receita bruta foram inferiores aos da contribuição sobre a folha (BRASIL, 2012).

\section{A SAÚDE E O SISTEMA ÚNICO DE SAÚDE}

Durante os governos do PT, não se pode dizer que houve avanços no sentido da implantação do Sistema Único de Saúde (SUS), muito embora importantes políticas tenham sido desenvolvidas, entre as quais se destaca o Programa Mais Médico (que garantiu a presença de médicos nos grotões do país), tão execrado pela direita que se mobilizou nas ruas pedindo o impeachment de Dilma. Ao contrário, pode-se dizer que houve retrocessos importantes, tal como é apontado mais adiante.

Do ponto de vista do gasto público, enquanto percentual do PIB, houve uma pequena melhora durante os governos Lula e Dilma: de 3,2\%, em 2002, passou a 3,9\% em 2015; percentual que se manteve constante nos últimos três anos. Mas o mais importante é que o nível do gasto público com saúde continuou e continua 
insuficiente, bem abaixo da média praticada nos países com sistemas públicos similares $(8 \%)^{7}$, o que resulta num gasto per capita bastante baixo. Chama a atenção, ainda, que durante esse período, aumentou a participação dos municípios e estados no gasto público em saúde, perante uma diminuição do governo federal.

Evidentemente que não podemos atribuir aos governos Lula e Dilma os problemas de fundo que estão relacionados ao SUS, tal como o fato de a sociedade brasileira, apesar da Constituição de 1988, não ter, a rigor, optado por construir um sistema público como ocorreu em outros países. Mas é possível se dizer que nada foi feito no sentido contrário, sendo mantido e mesmo aprofundado alguns dos determinantes do desenvolvimento em paralelo e concorrente ao SUS de um forte setor privado. Entre esses determinantes que favorecem o setor privado, destaca-se a renúncia fiscal decorrente da permanência de incentivos aos seguros e planos de saúde e às demais modalidades da assistência saúde privada nas deduções para efeito da base sobre a qual incide o imposto de renda das pessoas físicas e jurídicas.

Para se ter uma ideia da importância desse setor, em março de 2016 a saúde suplementar era composta por 1.125 operadoras, sendo 806 médico-hospitalares e 319 exclusivamente odontológicas, cobrindo $25,2 \%$ e $11,2 \%$, respectivamente, da população brasileira (ANS, 2016). Junto a esse setor, desenvolve-se um também expressivo segmento privado financiado diretamente por seus usuários no momento do consumo dos cuidados, mas cujo gasto pode ser declarado no imposto de renda de maneira a reduzir a base sobre o qual o imposto é calculado. O mais interessante é constatar que durante os governos do PT aumentou a taxa de cobertura dos planos de assistência médica: de $18,9 \%$, em dezembro de 2004, para $26 \%$ em dezembro de 2014, reduzindo-se esse percentual nos meses seguintes, quando a economia começou a entrar em recessão. Provavelmente parte do aumento da cobertura dos planos é explicada pela ampliação da formalização do emprego observada nos governos Lula e Dilma (esta, até 2014), tendo em vista que, desde a década dos 1970, os planos de saúde faziam parte da pauta de reivindicação dos trabalhadores mais organizados. Pouco a pouco esse item foi incorporado nas demandas dos demais trabalhadores do mercado formal de trabalho. Para isso, não foi desprezível o impulso concedido pela grande mídia televisiva e escrita - sempre disposta a defender que o setor privado tem melhores condições de prestar assistência médica do que o setor público.

O aumento do gasto público com saúde como proporção do PIB pode ser explicado pelos efeitos da aprovação da Emenda Constitucional no 29 (EC-29), ocorrida em agosto de 2000. Essa Emenda definiu que os estados e municípios alocassem, no primeiro ano, pelo menos, $7 \%$ de suas receitas de impostos, nelas compreendidas as transferências constitucionais, e que esse percentual deveria aumentar até atingir, em 2004, 12\% para os estados e $15 \%$ para os municípios, no mínimo. Já para a União, ela determinou que, para o primeiro ano, deveria ser aplicado pelo menos $5 \%$ a mais com relação ao orçamento empenhado do período

${ }^{7}$ Alemanha, Espanha, França, Reino Unido e Suécia. 
anterior; para os seguintes, o valor apurado no ano anterior seria corrigido pela variação do PIB nominal. O problema foi que a regulamentação dessa Emenda demorou longos oito anos, de modo que até lá não havia nenhum instrumento legal que definisse o que era gasto em ações e serviços de saúde SUS, muito embora consensos sobre a matéria tivessem sido construídos entre o Ministério da Saúde, os demais gestores e tribunais de conta, por exemplo. A partir da Lei 141/2012, quando finalmente a Emenda foi regulamentada, não era mais possível se considerar como gasto SUS a despesa com aposentadoria de funcionários da saúde, por exemplo, ou a despesa com saúde de um hospital que atendesse somente servidores.

As grandes surpresas, no entanto, estavam reservadas para ocorrerem no início do segundo mandato de Dilma. Em 19 de janeiro de 2015, a Lei 13.097/15 introduziu novas e amplas exceções à vedação constitucional à participação direta ou indireta de empresas ou capitais estrangeiros nas atividades de assistência à saúde. Até então, o texto constitucional e a lei orgânica da saúde (Lei n ${ }^{\circ} 8.080$, de 1990) previam que a presença do capital estrangeiro na assistência à saúde poderia ocorrer somente em casos de exceção e não em regra. A rigor, na interpretação das entidades que compõem o Movimento da Reforma Sanitária, nenhuma vedação estava mantida na Medida Provisória que havia sido aprovada pela Câmara dos Deputados (MP 656/14) e que foi encaminhada ao Poder Executivo como projeto de Lei de Conversão ${ }^{\circ}$ 18, que deu origem à Lei 13.097/15.

A simples dicção dos casos do art. 23, da Lei n 8.080 de 1991, com a alteração proposta no Projeto de Lei de Conversão da MP n 656 de 2014, esconde a amplitude do que, agora, se pretende permitir ao capital estrangeiro, a atuação na assistência à saúde por meio de:

a) hospitalares gerais ou especializados, incluindo a filantropia;

b) clínica geral, especializada, policlínica;

c) laboratórios de genética humana;

d) produção e fornecimento de medicamentos e produtos para a saúde;

e) laboratórios de análises clínicas, anatomia patológica e de diagnósticos por imagem.

Todas as atividades de assistência à saúde estão previstas no referido artigo do PL, restando a pergunta: o que está vedado? Qual é a exceção à vedação constitucional? A Constituição não permite a participação de empresas e do capital externo na saúde, mas o título do capítulo, bem como a redação do caput do art. 23 do PL de conversão, abre a saúde ao capital estrangeiro ignorando o texto constitucional. A referida redação é de positivação e não de negativa, conforme determina a Constituição ao vedar a participação estrangeira na saúde, salvo nos casos previstos em lei (ABrES, 2015).

Essa interpretação era completada por:

Com a autorização da entrada de capital estrangeiro no setor de saúde, empresas de fora do país poderão instalar ou operar hospitais 
(inclusive filantrópicos) e clínicas, além de executar ações e serviços de saúde. Atualmente, o capital estrangeiro está restrito aos planos de saúde, seguradoras e farmácias (ABrES, 2015).

Para essas entidades, ainda, a entrada do capital estrangeiro na saúde tinha o seguinte significado:

O domínio pelo capital estrangeiro na saúde brasileira inviabiliza o projeto de um Sistema Único de Saúde e consequentemente o direito à saúde, tornando a saúde um bem comerciável, ao qual somente quem tem dinheiro tem acesso. Com a possibilidade do capital estrangeiro ou empresas estrangeiras possuírem hospitais e clínicas - inclusive filantrópicas, podendo atuar de forma complementar no SUS - ocorrerá uma apropriação do fundo público brasileiro, representando mais um passo rumo à privatização e desmonte do SUS (ABrES, 2015).

Para se ter uma noção da dimensão dessa aprovação, para além de seu impacto no aumento da concentração das atividades em saúde e no SUS, é preciso lembrar que a vedação à entrada do capital estrangeiro no setor era um dos pontos-chave considerados pelo Movimento Sanitarista, movimento que impulsionou todas as reformas que resultaram na criação do sistema público universal de saúde, na Constituição de 1988. Dessa forma, a mudança promovida por Dilma, ao sancionar a Lei 13.097/15, significou uma ruptura com a tradição desse movimento.

Pouco tempo depois, em 17/03/2016, era a vez da segunda surpresa se fazer presente. $\mathrm{Na}$ Emenda Constitucional n. ${ }^{\circ} 86 / 2015$, que institui a obrigatoriedade de execução das emendas parlamentares, foi incluída nova regra para a aplicação dos recursos do governo federal na saúde (arts. $2^{\circ}$ e $3^{\circ}$ ), alterando a base de cálculo anteriormente existente (montante apurado no ano anterior corrigido pela variação nominal do PIB) por um percentual da Receita Corrente Líquida (RCL). No primeiro ano (2016) seria $13,2 \%$ da RCL, até alcançar $15 \%$. Isso resultou em perda de recursos para o SUS já no primeiro ano de R \$ 9,2 bilhões, segundo Funcia $(2015)^{8}$.

\section{A POLÍTICA DE ACESSO À EDUCAÇÃO SUPERIOR}

No campo da educação superior, a principal marca das políticas dos governos de Lula e Dilma é a ambiguidade. Se, de um lado, o país conheceu uma ampliação sem precedentes no acesso à educação superior pública, com rápida elevação de vagas gratuitas para estudantes de escolas públicas, estudantes de baixa renda e autodeclarados negros, pardos e indígenas, por outro lado, nunca foi tão expressi-

\footnotetext{
${ }^{8}$ No momento do fechamento deste texto, tramitava no Congresso Nacional a Proposta de Emenda Constitucional $n^{\circ} 241$, de 2016, que propõe congelar por vinte anos as despesas primárias do governo federal a partir de 2017, abolindo, portanto, as garantias de aplicações mínimas em saúde e educação.
} 
vo o domínio do setor privado lucrativo e de baixa qualidade na oferta educacional, assim como sua capacidade de influência na política educacional.

A segmentação de oportunidades nesse campo levou os críticos da privatização a afirmar que, na realidade, para a maioria que passou a frequentar a educação superior nos últimos anos, não houve democratização efetiva, mas uma "[...] uma expansão da educação superior que a mantém como de elite e de alta qualificação para poucos, enquanto adquire traços de 'sistema' de massas e de baixa qualificação para muitos" (Sguissardi, 2015, p. 869). Nesta parte do artigo, analisamos o legado do PT na educação superior, com ênfase nas políticas públicas de promoção do acesso às classes populares.

Do ponto de vista do financiamento da educação, a União assumiu parcela relativamente pequena do conjunto dos gastos públicos. A participação federal no gasto total em educação evoluiu de $0,9 \%$ do PIB entre 2000 e 2003 - primeiro ano do governo Lula -, caiu a 0,8\% durante tal governo, entre 2004 e 2005, e iniciou uma trajetória de crescimento em 2006 até alcançar 1,2\% do PIB em 2012. Neste mesmo ano, estados e municípios aportaram, cada, 2,4\% do PIB em educação, com o que se alcançou o patamar de $6 \%$ do PIB. Portanto, no período, apesar do aumento do gasto do governo federal, ampliou-se a distância entre este e o gasto de estados e municípios em educação. Em 2013, o gasto total foi de 6,1\% do PIB, sendo 5\% em educação básica e 1,1\% em educação superior. Em 2002, último ano de FHC, o gasto total estimado em educação foi de 4,8\% do PIB, sendo 0,9\% em educação superior (INEP, 2015a).

Apesar de relativamente limitado quanto ao percentual do PIB, o gasto federal em educação sofreu notável expansão a partir de 2006, ano em que há uma evidente correção de rumo na gestão do Ministério da Educação (MEC). Estagnado em torno de R \$ 40 bilhões anuais entre 2000 e 2006, o orçamento do MEC eleva-se progressivamente até 2014, quando alcança R \$ 114 bilhões. Em 2015, já com a economia em crise, cai levemente a R \$ 112 bilhões e a expectativa é que, em 2016, haja uma forte redução (Ministério da Fazenda, 2016).

No período, houve relevantes alterações na estrutura jurídica do financiamento, que levaram à ampliação dos recursos vinculados à educação. O Fundo de Manutenção e Desenvolvimento da Educação Básica (Fundeb), criado na Emenda Constitucional (EC) $n^{\circ}$ 53/2006, obriga uma maior participação da União no financiamento da educação básica. O Fundeb, a expansão da rede federal de educação superior e tecnológica e a ampliação dos repasses voluntários a municípios e estados foram os principais fatores a impulsionar a elevação do gasto da União em educação (Davies, 2016). Além disso, a EC n 59/2009, excluiu as receitas de impostos vinculadas à educação (Constituição, art. 212, caput) do âmbito de incidência da Desvinculação de Receitas da União (DRU) ${ }^{9}$. Com isso, a partir de 2011, foi

\footnotetext{
${ }^{9}$ A Emenda Constitucional n ${ }^{\circ} 93$, de 8 de setembro de 2016, prorrogou e aumentou de $20 \%$ para $30 \%$ a DRU até 2023, não incidindo, entretanto, nas despesas obrigatórias em educação. Também foram criadas a desvinculação de receitas de estados, municípios e distrito federal.
} 
retomada a obrigação de aplicação de no mínimo $18 \%$ da receita federal de impostos em ensino, obrigação que estava suspensa desde 1994. Na prática, entre 2011 e 2015 a média federal de aplicação da receita de impostos em educação foi de 22,7\%, conforme auditorias do Tribunal de Consta da União (INEP, 2015b). Além disso, a Lei $n^{\circ} 12.858$, de 2013 , destina $75 \%$ dos royalties e participações especiais do petróleo para a educação e $25 \%$ para a saúde, além de determinar que $50 \%$ dos recursos do Fundo Social do Pré-Sal, composto pelos recursos que a União recebe da exploração dessa área específica, sejam destinados a esses dois setores. Ainda que seus efeitos sejam incipientes, há expectativa de que esta norma venha a assegurar relevantes recursos suplementares à educação, sobretudo aos investimentos na ampliação das redes de ensino públicas.

Cresceu também, no período, o gasto público indireto em educação, que é o repasse de recursos públicos para a oferta de vagas gratuitas junto à iniciativa privada. Na educação superior, o gasto indireto deve-se principalmente ao Programa Universidade para Todos (ProUni) e ao Fundo de Financiamento Estudantil (Fies). Estimativas indicam que o gasto com esses programas elevou-se, entre 2010 e 2014, de R 578 milhões para R \$ 1,125 bilhão no ProUni e de R \$ 1,6 bilhão para impressionantes R\$12 bilhões no caso do Fies (Pinto, 2016).

Como resultado de um crescimento constante no período, o ensino de graduação registrou no Brasil 7,840 milhões de matrículas em 2014, contra 3,480 milhões em 2002. Eram, em 2014, 5,867 milhões (74,9\%) em instituições privadas e 1,961 milhão $(25,1 \%)$ em públicas, dividindo-se as matrículas públicas em 1,18 milhão na rede federal, 616 mil nas redes estaduais e 165 mil em instituições municipais. Em 2002 eram 2,428 milhões $(69,8 \%)$ de matrículas na rede privada contra 532 mil federais, 416 mil estaduais e 104 mil municipais (30,2\%) (INEP, 2005, 2015c).

A ampliação do acesso ao ensino superior federal público, nesse sentido, pode ser considerada a principal marca positiva dos governos do PT na educação. Foi mais do que dobrado o número de vagas ofertadas a cada ano em universidades públicas e institutos federais de ensino tecnológico. Ampliou-se em 86\%, entre 2003 e 2014, o número de matrículas em cursos de graduação presenciais na rede federal, superando a ampliação dessa modalidade na rede privada (INEP, 2005, 2015c). Ainda assim, quando considerado o total de matrículas (presenciais e semipresenciais), o crescimento da rede federal foi superado pelo setor privado, em parte resultado de forte incentivo estatal a partir de 2010.

No período foram criadas 18 novas universidades federais, totalizando $63 \mathrm{em}$ 2014. Também foi significativo o processo de ampliação daquelas existentes, impulsionado pelo Programa de Apoio a Planos de Reestruturação e Expansão (Reuni), cujo objetivo foi otimizar a oferta em instituições já consolidadas e promover sua interiorização com a criação de novos campus universitários. Estes mais do que dobraram no período, alcançando 331 campus no país (INEP, 2015c).

Essa ampliação foi acompanhada da consolidação da política de cotas. Em uma primeira fase, entre 2006 e 2011, cotas sociais e raciais foram implantadas em universidades federais específicas, de forma descentralizada e por decisão das próprias instituições. Em 2011 foram julgadas as ações que questionavam essas cotas, 
consideradas então plenamente adequadas à Constituição pelo Supremo Tribunal Federal (STF) em julgamento de grande visibilidade pública, fato que levou à consolidação e institucionalização como política pública federal. Foi então aprovada a Lei n. 12.711, de 2012, que determina a adoção de cotas sociais e etnicorraciais em $50 \%$ do total de vagas nas instituições federais de ensino superior, que deveriam ser destinadas a alunos oriundos de escolas públicas. Esse percentual deve também contemplar a reserva de $25 \%$ do total de vagas para alunos com renda familiar per capita inferior a 1,5 salário mínimo e, dentro de cada um dos estratos de renda, devem ser asseguradas cotas específicas para negros, pardos e indígenas na proporção de sua participação na população do estado em que está localizada a instituição.

Hoje todas as instituições federais de ensino adotam tais cotas na seleção de ingresso, realizada através do Sistema de Seleção Unificado (Sisu). Implantado pelo MEC em 2010, constitui também uma relevante medida de inclusão, já que possibilita ao conjunto dos estudantes a candidatura em diferentes instituições ao mesmo tempo, com uma mesma nota extraída do Exame Nacional do Ensino Médio (Enem), exame gratuito para os alunos de escola pública.

Apesar de recentes, o efeito dessas medidas já pode ser percebido no aumento da participação relativa das populações não brancas e de menor renda (Gráfico 1).

\section{Gráfico 1: Graduandos no Ensino Superior Público, por cor e faixa de rendimento familiar, 2003 a 2014}

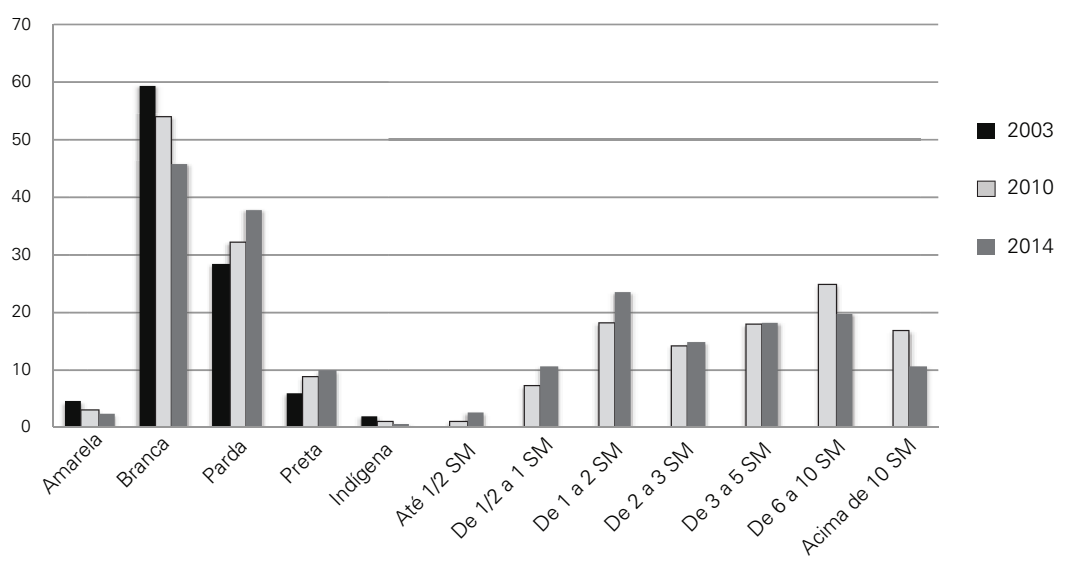

Fonte: Andifes, 2016.

Vê-se, portanto, que hoje as universidades públicas são majoritariamente ocupadas por estudantes não brancos, são mais populares, além de oferecerem um número maior de vagas ao conjunto da população. De todas as mudanças promovidas pelo PT nas políticas sociais, talvez esta seja a mais significativa por seu caráter simbólico e distributivo. As universidades públicas no Brasil eram expressão flagrante de nossos esquemas de privilégio e exclusão, quadro que começa a ser revertido no período estudado. A mudança de perfil do alunado, por sua vez, exige 
mais recursos para programas de assistência estudantil e bolsas, do contrário, torna-se ineficaz, na prática, a maior abertura conquistada.

Se a retomada do investimento na ampliação das universidades públicas é uma marca que diferencia Lula e Dilma dos governos civis anteriores, a abertura e o estímulo à ampliação do setor privado nos governos petistas são mais que meras linhas de continuidade em relação a esses governos.

Sob Lula e Dilma, o setor privado lucrativo que explora a educação superior encontrou inéditas condições de ampliação e lucratividade, resultando na formação de um oligopólio. Como resultado da conjugação de investimentos estatais e abertura de capital na bolsa, o setor educacional do mercado de ações foi o mais lucrativo na Bovespa. Entre agosto de 2012 e agosto de 2014, enquanto o Ibovespa viu uma redução de $3,67 \%$, as ações das principais empresas do ramo educacional tiveram espantosa valorização, $314 \%$ no caso da Kroton e $241 \%$ da Estácio (Sguissardi, 2015).

A capitalização desses grupos permitiu uma concentração de mercado sem precedentes, tanto em razão de aquisições e fusões entre grupos como da eliminação de instituições de ensino tradicionais. Em 2013, os três principais grupos educacionais com ações em bolsa (Kroton, Anhanguera e Estácio) concentravam nada menos que $23,4 \%$ de toda a oferta do setor privado (Maia, 2014). Com a recente aquisição da Anhanguera pela Kroton, esta passou a mais de 1 milhão de matrículas, tornando-se o maior grupo educacional do mundo em valor de mercado (Forbes, Brasil 2015). Conjugou-se, portanto, a dinâmica do capitalismo financeiro à crescente pressão por ampliação de acesso à educação superior, não absorvida nas instituições estatais. Em um país tão desigual como o Brasil, entretanto, a formação de um mercado consumidor dependia da ação Estatal, o que de fato se materializou no Fies e no ProUni.

O Fies foi criado em 1999, no governo de FHC, sendo regulado pela Lei n. 10.260/2001. Tem origem em 1975, quando foi instituído o Crédito Educativo, seu antecessor direto. Trata-se de um empréstimo subsidiado aos estudantes, com taxas abaixo das praticadas no mercado. Desde 2010, após reformulação, o Fies assume a posição de principal política estatal para a ampliação do acesso à educação superior. Impulsionado por uma taxa negativa de juros, de 3,4\% ao ano, pelo alongamento do prazo de amortização e de carência e descontos para determinadas carreiras, os contratos do Fies mais do que decuplicaram. Em 2014, nada menos que $35 \%$ das matrículas da rede privada eram financiadas pelo programa (Pinto, 2016).

O ProUni foi criado em 2004 e transformado na Lei n. 11.096/2005. Pelo programa, ficam as instituições privadas isentas de imposto de renda e de contribuições para a seguridade social, desde que ofereçam bolsas integrais ou parciais a estudantes oriundos de escolas públicas e cuja renda familiar mensal per capita, respectivamente, não exceda o valor de até 1,5 ou 3 salários mínimos mensais. Ao aderir ao programa as instituições comprometem-se a oferecer ao menos uma bolsa integral do ProUni para cada 10,7 estudantes pagantes. Além disso, comprometem-se a incorporar os critérios de cotas para pessoas com deficiência ou estudan- 
tes autodeclarados indígenas e negros, em quantidade não inferior à participação desses cidadãos no conjunto da população do estado. Como não é incomum existência de vagas pagas ociosas nas instituições privadas, na prática, aderir ao ProUni é um grande negócio para o setor, já que assim libera-se de tributos importantes sem com isso assumir custos na mesma proporção. Para o governo também se mostrou uma vantagem, já que passou a oferecer, pelo programa, vagas gratuitas de baixo custo, consequentemente reduzindo a pressão de demandantes não incluídos nesse nível de ensino.

Enquanto o governo exaltava seu caráter inclusivo, setores à esquerda criticaram a aliança com os empresários da educação e a decisão de repassar indiretamente recursos públicos para esse setor, recursos que poderiam ser arrecadados e aplicados no setor público educacional (Corbucci, 2004). Representaria o programa uma falsa democratização, já que o acesso se daria em instituições privadas de qualidade duvidosa (Carvalho, 2006, 2014). O fato é que, a um baixo custo relativo, o ProUni passou a oferecer um número crescente de bolsas, iniciando com 112 mil em 2005 e chegando à oferta de 307 mil bolsas em 2014, sendo um terço destas integrais (Sisprouni, 2015). O sucesso e consolidação do ProUni durante os governos Lula resultou na diminuição das resistências ao programa.

A legitimação do ProUni aliada a seus limites intrínsecos de expansão, dado o desenho institucional do programa, deram base à reformulação do Fies em $2010 \mathrm{e}$ à sua inédita expansão durante o primeiro mandato de Dilma. Essa rápida expansão também foi objeto de duras críticas, sobretudo porque foi o principal fator a promover a massificação de baixo custo e de baixa qualidade. Além disso, percebeu-se, com os primeiros sinais de crise, que é altíssimo o risco de inadimplência dos beneficiários, como já ocorreu na experiência do Crédito Educativo (Costa, 2015). Como forma de conter esses riscos e ante as restrições orçamentárias que se anunciavam, em dezembro de 2014 o MEC editou duas portarias endurecendo os critérios para concessão dos empréstimos aos estudantes. A partir de então, os candidatos devem apresentar uma nota mínima no Enem, exigência que, de pronto, excluiu um terço dos beneficiários. Em consequência disso, as quatro companhias participantes da Bovespa perderam, entre janeiro e abril de 2015 , de $30 \%$ a $50 \%$ do valor de suas ações (Sguissardi, 2015). Após praticamente 10 anos de uma bem-sucedida parceria público-privada na oferta de acesso à educação superior, que de um lado minimizou a pressão popular por vagas nas instituições públicas e de outro assegurou taxas de lucro descomunais ao setor privado, essa foi a mais significativa medida de regulação do setor adotada nos governos do PT, gerando forte descontentamento entre os empresários da educação (Hoper Consultoria, 2015).

\section{CONSIDERAÇÕES FINAIS}

Do que foi exposto, pode-se dizer que as políticas sociais realizadas pelos governos Lula e Dilma, no campo da Seguridade Social, na implantação e desen- 
volvimento do Programa Bolsa Família, em relação ao salário mínimo e na educação superior apresentam um duplo caráter. De um lado, não há dúvida de que constituíram um avanço, melhorando as condições de vida e de reprodução das parcelas mais pobres do país. É isso que foi feito mediante o massivo BF e a valorização do salário mínimo. Mas, de outro, note-se que a via ou o instrumento eleito para que essa melhora ocorresse foi a renda ou o salário, mantendo-se, em geral, sem alteração as estruturas seculares que geram a pobreza e a desigualdade no país.

Nesse sentido, a política de acesso à educação superior significa uma exceção, já que os estudantes de classes populares que passaram a acessar a universidade por conta da ampliação de vagas gratuitas e das cotas podem assim romper o histórico familiar de inserção precária nos campos econômico e cultural. Esse efeito ainda não foi integralmente percebido e documentado. Além de muito recente para que possa apresentar seus efeitos, vale destacar também que continua muito limitada a oportunidade de acesso à universidade pelos mais pobres. Só uma parcela das vagas públicas e do ProUni os contemplam, enquanto 93,9\% dos jovens de 18 a 24 anos pertencentes ao quartil mais pobre está fora das universidades (IBGE, 2015).

Muitas das políticas, por mais importantes que tenham sido, não trazem o traço da perenidade, podendo ser facilmente revertidas caso a correlação de forças existente na sociedade assim permitir. Além do mais, no caso do benefício concedido pelo Bolsa Família, ele não constitui um direito, o que facilita o surgimento de propostas de redefinição de sua cobertura, tal como está sendo aventado pelo governo usurpador de Michel Temer.

Ao mesmo tempo, naquilo que está no campo dos direitos sociais ou que define as regras sobre as quais se organiza a proteção social, com exceção da fórmula 85/95 e de algumas medidas na educação, a atuação dos governos Lula e Dilma caminhou no sentido da piora da situação dos segurados (introdução do critério de idade para a aposentadoria dos servidores e o início da cobrança de contribuição dos aposentados), da manutenção do incentivo da alternativa de mercado (planos de saúde e permanência do subfinanciamento do SUS) e da permissão aberta ou mesmo incentivo à atuação do grande capital (especialmente na área da saúde, com o franqueamento do capital estrangeiro, e na educação, com a expansão do crédito necessário à expansão e financeirização do setor lucrativo).

Desse ponto de vista, muito embora os governos do PT certamente venham a passar à história como aqueles que fizeram políticas para os mais pobres do país, sendo Lula lembrado como um "novo pai dos pobres", tal como Getúlio Vargas ainda o é, foram governos que, apesar de se dizerem progressistas, pouco contribuíram para o avanço institucional da proteção social organizada e garantida pelo Estado, enquanto foram determinantes na consolidação do setor privado na área. A análise das políticas de acesso à educação superior é exemplar nesse sentido. Ao mesmo tempo em que foi ampliada a participação das universidades públicas federais no total da oferta, também cresceu o setor privado, saltando este de cerca de $70 \%$ da oferta, em 2003, para quase $75 \%$ no final do período estudado, com 
grande crescimento das instituições lucrativas apoiadas pelo Estado e do ensino à distância (INEP, 2015c, 2005).

De certa maneira, a atuação de Lula e Dilma no campo social reproduz a contradição mais geral presente em suas gestões: atuar como se fosse possível atender ao mercado e aos credores e, ao mesmo tempo, promover crescimento e desenvolvimento econômico. Em outras palavras, que era possível servir a dois senhores. Tal como a exigência do superávit primário impunha limites estreitos para a atuação indutora do Estado na economia, ela impedia a destinação dos recursos necessários para que o SUS de fato se tornasse um sistema público universal e para que a educação superior viesse a se tornar um potente mecanismo de superação das desigualdades de oportunidades, também atuava para que a Previdência Social estivesse sempre sobre a mira de propostas de reforma.

\section{REFERÊNCIAS BIBLIOGRÁFICAS}

AGÊNCIA NACIONAL DE SAÚDE SUPLEMENTAR - ANS (2016). Dados gerais. Disponível em http://www.ans.gov.br/perfil-do-setor/dados-gerais. Acesso em 22 de junho de 2016.

ASSOCIAÇÃO BRASILEIRA DE ECONOMIA DA SAÚDE - ABrES (2015). "Por que somos contrários ao capital estrangeiro na atenção à saúde: Veta Presidenta Dilma!”. Disponível em http:// abresbrasil.org.br/por-que-somos-contrarios-ao-capital-estrangeiro-na-atencao-saude-veta-presidenta-dilma.html Acesso em 13 de julho de 2016.

ASSOCIAÇÃO NACIONAL DOS DIRIGENTES DAS INSTITUIÇÕES FEDERAIS DE ENSINO SUPERIOR- ANDIFES (2016). Relatório do Perfil Socioeconômico e Cultural dos Estudantes de Graduação das Universidades Federais Brasileiras. Disponível: http://www.andifes.org.br/categoria/documentos/biblioteca/publicacoes-andifes/

BANCO MUNDIAL (2000) World Development Report 2000/2001: Attacking Poverty. Washington, D. C, Oxford University Press.

BRASIL - Ministério da Fazenda (2012). “Desoneração será de aproximadamente R \$ 60 bilhões nos próximos quatro anos”. Brasília. Disponível em: http://www.mpas.gov.br/conteudoDinamico. php?id=399. Acesso em: 11 maio 2013.

CARVALHO, C. H. A. (2006) "O PROUNI no governo Lula e o jogo político em torno do acesso ao Ensino Superior”. Campinas, Educação \& Sociedade, v. 27, n. 96, especial, p. 979-1000, outubro.

CARVALHO, C.H.A. (2014) "Política para a educação superior no governo Lula: expansão e financiamento." Revista do Instituto de Estudos Brasileiros, n. 58, p. 209-244.

COMISSÃO ECONÔMICA PARA A AMÉRICA LATINA E O CARIBE - CEPAL, (2000) Panorama social da América Latina - 1999-2000. Santiago do Chile.

COMISSÃO ECONÔMICA PARA A AMÉRICA LATINA E O CARIBE - CEPAL (2009) Panorama social da América Latina - 2009. Santiago do Chile.

CORBUCCI, P. R. (2004) "Financiamento e democratização do acesso à educação superior no Brasil: da deserção do Estado ao projeto de reforma”. Educação \& Sociedade, Campinas, v. 25, n.88, Especial, p.677-701.

COSTA, F.N. (2015) “Crédito educativo: alto risco de inadimplência, aqui e nos EUA”. Disponível em: https://fernandonogueiracosta.wordpress.com/2015/04/01/credito-educativo-alto-risco-de-inadimplencia-aqui-e-nos-eua/

DAVIES, N. (2016) “A política educacional dos governos do PT: continuidades ou descontinuidades em relação aos do PSDB?”. Revista HISTEDBR On-line, Campinas, SP, v.16, n.67, p. 39-52.

ESTADÃO - O ESTADO DE SÃO PAULO (2016). "Programas sociais de Temer vão focar os $5 \%$ mais 
pobres”. Disponível em http://politica.estadao.com.br/noticias/geral,programas-de-temer-vao-focar-os-5-mais-pobres,10000028512. Acesso em 10/07/2016.

FGV - FUNDAÇÃO GETÚLIO VARGAS (2001). Conjuntura Econômica, Rio de Janeiro, v.55, nº10, out. 2001.

FORBES BRASIL (2015) “Educação torna-se negócio rentável para acionistas no Brasil”. Disponível em: http://www.forbes.com.br/negocios/2015/02/educacao-torna-se-nogocio-rentavel-para-acionistas-no-brasil/

FUNCIA, Francisco (2015) “Quanto o ministério da saúde precisará ter no orçamento de 2016 para manter o padrão de gastos de 2014 em ações e serviços públicos de saúde (asps)?”. Idisa. Domingueira n. ${ }^{\circ}$ 21, 04/Outubro. Disponível em: http://www.idisa.org.br/img/File/Domingueira \% 20 da $\% 20$ Sa $\%$ C3\%BAde $\% 20-\% 20021 \% 202015 \% 20-\% 2004 \% 2010 \% 202015$.pdf. Acesso em $12 / 07 / 2016$.

HOPER CONSULTORIA (2015) "O impacto das mudanças do Fies na educação superior brasileira”. Disponível em: http://www.hoper.com.br/single-post/2015/02/12/ O-IMPACTO-DASMUDAN\%C3\% 87AS-DO-FIES-NA-EDUCA \%C3\% 87\%C3\% 83O-SUPERIOR-BRASILEIRA

IBGE (2015) Pesquisa Nacional por Amostra de Domicílios. Brasília, DF.

INEP (2015a) Censo da Educação Superior 2014 - Notas Estatísticas. Brasília, DF: Ministério da Educação. Disponível: http://download.inep.gov.br/educacao_superior/censo_superior/documentos/2015/notas_sobre_o_censo_da_educacao_superior_2014.pdf

INEP. (2005) Censos da Educação Superior - Resumo Técnico 2004. Brasília, DF: Ministério da Educação. Disponível: http://download.inep.gov.br/download/superior/2004/censosuperior/Resumo_ tecnico-Censo_2004.pdf

INEP. (2015b) Demonstrativo de Manutenção e Desenvolvimento do Ensino (MDE) Federal, 2015b. Disponível: http://portal.inep.gov.br/estatisticas-gastoseducacao-mde-demo_mde_federal

INEP. Investimentos Públicos em Educação. Brasília, Instituto Nacional de Estudos e Pesquisas Educacionais Anísio Teixeira, setembro, 2015a. Disponível: http://portal.inep.gov.br/estatisticas-gastoseducacao

INSTITUTO DE PESQUISAS APLICADAS (2010). Objetivos de Desenvolvimento do Milênio - Relatório Nacional de Acompanhamento. Brasília, IPEA. Disponível: http://agencia.ipea.gov.br/images/stories/PDFs/100408_relatorioodm.pdf. Acessado em 08/07/ de julho de 2011.

MAIA, S. (2014) "Mercado nota 10 - Com empurrão público, as faculdades privadas atraem investidores”. Carta Capital Ano XX, n. 799.

MARQUES, Rosa Maria (2005) “A importância do Bolsa Família nos municípios brasileiros”. Cadernos de Estudos Desenvolvimento Social em Debate, n.1. Brasília: Ministério do Desenvolvimento Social e Combate à Fome, Secretaria de Avaliação e Gestão da Informação.

MARQUES, Rosa Maria e MENDES, Áquilas. (2005) "Desvendando o social no governo Lula: a construção de uma nova base de apoio” In PAULO, João Antonio de (org.) Adeus ao desenvolvimento. Belo Horizonte, Autêntica: p. 141-173.

MARQUES, Rosa Maria; LEITE, Marcel Guedes; MENDES, Áquilas; e FERREIRA, Mariana Ribeiro Jansen. (2009) "Discutindo o papel do Programa Bolsa Família na decisão das eleições presidenciais brasileiras de 2008". Revista de Economia Política, vol. 29, nº 1.

MARX, Karl. (1867 [1982]) O Capital. São Paulo: Difel.

MINISTÉRIO DA FAZENDA (2016). Sistema Integrado de Administração Financeira do Governo Federal. Disponível: http://www.tesouro.fazenda.gov.br/siafi

MINISTÉRIO DA PREVIDÊNCIA SOCIAL (vários anos) Aeps Infologo. Disponível em: < http:// www3.dataprev.gov.br/infologo/>. Acesso em 28/08/2016.

MINISTÉRIO DO DESENVOLVIMENTO SOCIAL E AGRÁRIO (MDSA). Disponível em: http://mds. gov.br/assuntos/bolsa-familia/o-que-e/beneficios Acesso em 10/07/2016.

NERI, Marcelo Côrtes; VAZ, Fabio Monteiro e SOUZA, Pedro Herculano Guimarães Ferreira de (2013) Efeitos macroeconômicos do Programa Bolsa Família: uma análise comparativa das transferências sociais. Brasília, IPEA. Disponível em http://www.ipea.gov.br/portal/images/stories/ PDFs/131015_bolsa_familia_cap11.pdf. Acesso em 09 de novembro de 2014. 
PINTO, José Marcelino de Rezende. (2016) "Uma análise da destinação dos recursos públicos, direta ou indiretamente, ao setor privado de ensino no Brasil". Educação \& Sociedade, Campinas, v. 37, n. 134 , p. 133-152.

RASELLA, DAVIDE (2013). Impacto do Programa Bolsa Família e seu efeito conjunto com a Estratégia Saúde da Família sobre a mortalidade no Brasil. Tese de doutorado. Instituto de Saúde Coletiva, Universidade Federal da Bahia.

SAWYER, Diana Oya (2007) Avaliação do impacto do Programa Bolsa Família. Brasília, MDS.

SGUISSARDI, Valdemar (2015) "Educação superior no Brasil. Democratização ou massificação mercantil?” Educação \& Sociedade, Campinas, v. 36, n. 133, p. 867-889.

SILVEIRA NETO, Raul da Mota (2010) "Impacto do Programa Bolsa Família sobre a frequência à escola: estimativa a partir de informações da Pesquisa Nacional por amostra de domicílio (PNAD)”. In: IPEA. Bolsa Família 2003 - 2010: avanços e desafios. Brasília: IPEA, volume 2, 2010.

SINGER, André (2009). "Raízes sociais e ideológicas do lulismo". Novos Estudos Cebrap, n 85.

SOARES, Sergei; SOUZA, Pedro Herculano G. Ferreira de; OSÓRIO, Rafael Guerreiro; SILVEIRA, Fernando Gaiger (2010) "Os impactos do benefício do Programa Bolsa Família sobre a desigualdade e a pobreza”. In: IPEA. Bolsa Família 2003 - 2010: avanços e desafios. Brasília: IPEA, volume 2.

SOLANO, Carlos Barba, coord. (2009) Proyecto: La reforma social en América Latina en la encrucijada. Transferencias condicionadas de ingresos o universalización de la proteción social. Fundación Carolina "Grupo de Trabajo Pobreza y Politicas Sociales. CLACSO. Acessível em http://pt.scribd. com/doc/56286801/Comparacion-Programa-Jefes-y-Jefas-de-Hogar-Desocupados-Plan-Familia-por-la-Inclusion-Social-y-Asignacion-Universal-por-Hijo-Argentina-Salta-Alva. 